\title{
Functional Similarity of Anticancer Drugs by MTT Bioassay
}

Takaki Hiwasa ${ }^{1 *}$,Takanobu Utsumi ${ }^{1}$, Mari Yasuraoka' ${ }^{1}$ Nana Hanamura', Hideaki Shimada ${ }^{2}$, Hiroshi Nakajima ${ }^{3}$, Motoo Kitagawa ${ }^{4}$, Yasuo $^{1}$ Iwadate $^{4,5}$, Ken-ichiro Goto ${ }^{6}$, Atsushi Takeda ${ }^{7}$, Kenzo Ohtsuka ${ }^{8}$, Hiroyoshi Ariga ${ }^{9}$ and Masaki Takiguchi ${ }^{1}$

${ }^{1}$ Department of Biochemistry, and Genetics, Chiba University, Graduate School of Medicine, Chuo-ku, Chiba 260-8670, Japan ${ }^{2}$ Department of Surgery, School of Medicine, Toho University, Ota-ku, Tokyo 143-8541, Japan

${ }^{3}$ Department of Molecular Genetics, Chiba University, Graduate School of Medicine, Chuo-ku, Chiba 260-8670, Japan

${ }^{4}$ Department of Molecular and Tumor Pathology, Chiba University, Graduate School of Medicine, Chuo-ku, Chiba 260-8670, Japan

${ }^{5}$ Department of Neurological Surgery, Chiba University, Graduate School of Medicine, Chuo-ku, Chiba 260-8670, Japan

${ }^{6}$ Department of Orthopaedic Surgery, National Hospital Organization, Shimoshizu Hospital, Yotsukaido, Chiba 284-0003, Japan

${ }^{7}$ Laboratory of Biochemistry, Graduate School of Nutritional Sciences, Sagami Women's University, Sagamihara, Kanagawa 252-0383, Japan

${ }^{8}$ Laboratory of Cell \& Stress Biology, Department of Environmental Biology, Chubu University, Matsumoto-cho, Kasugai, Aichi 487-8501, Japan

${ }^{9}$ Graduate School of Pharmaceutical Sciences, Hokkaido University, Kita-ku, Sapporo 060-0812, Japan

\begin{abstract}
We prepared normal or Ha-ras-transformed NIH3T3 cells transfected stably or transiently with various tumorrelated genes. The chemosensitivity of the transfected clones to 16 anticancer drugs was compared to the parental control cells using the MTT assay. The chemosensitivity changes induced by transfected genes were calculated and expressed numerically as the Drug Chemosensitivity Index (DCl). High DCl values (indicating resistance) were frequently observed in cells expressing C/EBPa, C/EBP 3 , p53, p21, PTEN, dominant-negative MDM2, caspases, HSP90, COUP-TF1 and decorin. In contrast, transfectants expressing ras, src, erbB2 and calpastatin had low $\mathrm{DCl}$ values, indicating increased sensitivity. Thus, it may be possible to predict the sensitivity of cancer cells toward anticancer drugs based on the expression levels of these genes. We then performed a regression analysis of $\mathrm{DCl}$ values between anticancer drugs. The correlation coefficients $(r)$ were relatively high between cisplatin, camptothecin, mitomycin $\mathrm{C}$ and etoposide, suggesting that the mechanisms of action of these drugs are similar. The $r$ values of aclarubicin, vincristine, taxol and cytarabine were low, suggesting that each of these drugs has a different and unique effect. This analysis may provide a rationale for design of combination chemotherapy regimens.
\end{abstract}

Keywords: Anticancer drugs; Cancer chemotherapy; MTT assay

Abbreviations: ACR: Aclarubicin; AraC: Cytarabine; CDDP: Cisplatin; CPT: Camptothecin; DMEM: Dulbecco's modified Eagle's minimum essential medium; DMSO: dimethyl sulfoxide; 5-FU: 5-fluorouracil; HU: hydroxyurea; IFM: ifosfamide; MCNU: methyl 6-[3-(2-chloroethyl)-3-nitrosoureido]-6-deoxy- $\alpha$-D-glucopyranoside; MIT: mitoxantrone; MMC: mitomycin C; MTT: 3-(4,5-dimethylthiazol-2-yl)-2,5-diphenyltetrazolium bromide; MTX: methotrexate; PBS: phosphate-buffered saline; PEP: peplomycin; PMSF: phenylmethylsulfonyl fluoride; Taxol: paclitaxel; 6-TG: 6-thioguanine; VCR: vincristine; VP-16: etoposide

\section{Introduction}

Chemotherapy using anticancer drugs is a useful therapeutic method for cancer. Thus far, many effective anticancer drugs have been developed. However, due to the adverse effects of each drug, their application is limited. Thus, combination therapy using smaller amounts of multiple drugs has become more and more common.

The efficacy of anticancer drugs varies among patients. This may be explained by differences in gene expression. For example, overexpression of $\mathrm{P}$-glycoprotein results in prominent resistance to many drugs such as vincristine, etoposide, and paclitaxel [1]. Comprehensive cDNA microarray analysis has been carried out for various cancers to examine alterations of gene expression [2-8].

In addition, a large diverse panel of cultured human tumor cell lines was tested for sensitivity to anticancer drugs [9]. Although this analysis was efficient to discriminate anticancer drug-responsive tumor cells, the genetic backgrounds of the cell lines were so variable that the precise action mechanism remained unclear. In the present study, we prepared NIH3T3 mouse fibroblasts transfected stably or transiently with varying tumor-related genes, and examined their chemosensitivity to anticancer drugs. Variations in action mechanisms may provide a rationale for combination chemotherapy.

\section{Materials and Methods}

\section{Chemicals}

Dulbecco's modified Eagle's minimum essential medium (DMEM), 3-(4,5-dimethylthiazol-2-yl)-2,5-diphenyltetrazolium bromide (MTT), 6-thioguanine (6-TG), cytarabine (AraC), hydroxyurea (HU) and were purchased from Sigma (St. Louis, MO). Mitomycin C (MMC), methotrexate (MTX), 5-fluorouracil (5-FU) and mitoxantrone (MIT) were purchased from Merck Biosciences (Darmstadt, Germany). Camptothecin (CPT) was purchased form Biomol Research Laboratories (Plymouth Meeting, PA). Paclitaxel (Taxol) was purchased from Alexis Corporation (Lausen, Switzerland). Dimethyl sulfoxide (DMSO), etoposide (VP-16), cisplatin (CDDP) and peplomycin (PEP) were ob-

*Corresponding author: Dr. Takaki Hiwasa, Associate Professor, Department of Biochemistry and Genetics, Chiba University, Graduate School of Medicine, 1-8-1 Inohana, Chuo-ku, Chiba 260-8670, Japan, Tel: 81-43-226-2541; E-mail: hiwasa takaki@faculty.chiba-u.jp

Received July 11, 2011; Accepted December 15, 2011; Published December 17,2011

Citation: Hiwasa T, Utsumi T, Yasuraoka M, Hanamura N, Shimada $\mathrm{H}$, et al. (2011) Functional Similarity of Anticancer Drugs by MTT Bioassay. J Cancer Sci Ther 3: 250-255. doi:10.4172/1948-5956.1000099

Copyright: ( 2011 Hiwasa T, et al. This is an open-access article distributed under the terms of the Creative Commons Attribution License, which permits unrestricted use, distribution, and reproduction in any medium, provided the original author and source are credited. 
Citation: Hiwasa T, Utsumi T, Yasuraoka M, Hanamura N, Shimada H, et al. (2011) Functional Similarity of Anticancer Drugs by MTT Bioassay. J Cancer Sci Ther 3: 250-255. doi:10.4172/1948-5956.1000099

tained from Wako Pure Chemicals (Kyoto, Japan). Vincristine (VCR) and ifosfamide (IFM) were obtained from Shionogi Pharmaceutica Co. Ltd. (Osaka, Japan); methyl 6-[3-(2-chloroethyl)-3-nitrosoureido]-6deoxy- $\alpha-\mathrm{D}$-glucopyranoside (MCNU) from Mitsubishi Welfarma Co. Ltd. (Osaka, Japan); and aclarubicin (ACR) from Astellas Pharma Inc. (Tokyo, Japan).

cDNA clones were purchased from Toyobo Biochemicals (Osaka, Japan), Guthrie Research Institute (Sayre, PA) or Open Biosystems (Huntsville, AL). Some clones were provided by isolators.

\section{Cell lines and culture}

NIH3T3 mouse fibroblasts and Ha-ras-transformed NIH3T3 cells (ras-NIH3T3) [10] were cultured in DMEM supplemented with 5\% bovine serum and $100 \mu \mathrm{g} / \mathrm{ml}$ of kanamycin. Cells were transiently or stable transfected with cDNAs in eukaryotic expression vectors such as pcDNA3 and pME18S-FL3. To isolate stable transfectants, cells were transfected with the expression plasmids together with the neo gene using LipofectAMINE reagent (Life Technologies, Carlsbad, CA), and then selected by culture in the presence of G418 $(400 \mu \mathrm{g} / \mathrm{ml})$ for two weeks as described [11-13]. A total of 135 stable transfectants and 41 transiently transfected cells were examined for chemosensitivity toward 16 anticancer drugs.

\section{Western-blotting and RT-PCR analyses}

The protein expression levels of transfected genes were examined by Western blotting $[12,13]$. The cells were washed with phosphatebuffered saline (PBS) and lysed in $0.5 \%$ Nonidet P-40, $20 \mathrm{mM}$ Tris- $\mathrm{HCl}$ (pH 7.5), $1 \mathrm{mM}$ EDTA, $1 \mathrm{mM}$ phenylmethylsulfonyl fluoride, $50 \mu \mathrm{M}$ leupeptin, $50 \mu \mathrm{M}$ antipain, $50 \mu \mathrm{M}$ pepstatin $\mathrm{A}$ and $50 \mu \mathrm{M}$ acetyl-LeucylLeucyl-norleucinal for $10 \mathrm{~min}$ at $4^{\circ} \mathrm{C}$. The cell lysate was centrifuged at $13,000 \times \mathrm{g}$ for $10 \mathrm{~min}$ and the supernatant was used as cytoplasmic cell extract. The pellet was used as the nuclear fraction. The samples were analyzed by Western blotting using antibodies purchased from Santa Cruz Biotechnology (Santa Cruz, CA), followed by detection using ImmunoStar Reagents (Wako Pure Chemicals).

When the commercial antibodies are not available, the mRNA expression levels were examined by RT-PCT (reverse transcriptionpolymerase chain reaction) as described previously [13,14]. Briefly, total cellular RNA was isolated from the tumor tissues using FastPure RNA Kit (Takara Biochemicals, Kyoto, Japan). Reverse transcription was carried out with oligo $(\mathrm{dT})_{20}$ primer using the ThemoScript RT-PCR System (Invitrogen, Carlsbad, CA), according to the manufacturer's instructions. The mRNA expression levels were examined via quantitative realtime RT-PCR using the Universal Probe Library system (Roche, Basel, Switzerland).

\section{Evaluation of cytotoxicity of anticancer drugs}

Chemosensitivity of transfected cells was examined using the MTT assay according to the method of Mosmann [15] as previously described [16,17]. Cells at exponentially growing phase were used. Five thousand cells per well $(100 \mu \mathrm{l})$ were plated in 96 -well plates in the presence of various concentrations of anticancer drugs, and cultured for three days. The activity of mitochondrial succinic dehydrogenase was measured by incubation for $4 \mathrm{~h}$ in the presence of $0.5 \mathrm{mg} / \mathrm{ml}$ of MTT (3-(4,5-dimethylthiozol-2-yl)-2,5-diphenyltetrazolium bromide). Absorbance reflects the viable cell number and was measured at 570 $\mathrm{nm}$ with a reference wavelength of $650 \mathrm{~nm}$ using a microplate reader.
Absorbance reflects the viable cell number and was expressed as a percentage of that of cells cultured in the absence of anticancer drugs.

For the combination treatment, ras-NIH3T3 were added with 5-FU (50 ng/ml), PEP (500 ng/ml) or MTX (50 ng/ml), and immediately after the addition, plated in the presence of varying concentrations of MIT, PEP or VP-16.

\section{Data mining}

The difference in the chemosensitivity between the parent and transfected cells was calculated and expressed numerically as the Drug Chemosensitivity Index (DCI) [17-19] as follows: DCI $=\log$ $\left(\mathrm{IC}_{40 \text {,transfectant }} / \mathrm{IC}_{40 \text {,parent }}\right)$ (Figure 1).

\section{Results and Discussion}

\section{Chemosensitivity to anticancer drugs of transfected cells}

Mouse fibroblasts, NIH3T3 or ras-NIH3T3, were transfected with various cancer-related genes, and the chemosensitivity to 16 different anticancer drugs was examined by MTT assay. Table 1 summarizes the list of genes of which the transfection induced resistance or sensitization against each anticancer drugs. The DCI values reflect the extent how resistant of the transfected cells were converted by the gene transfection [17-19]. The full version of list of DCI values are shown in Supplementary Table S1. High DCI values (indicating drug resistance) were frequently observed in cells expressing $\mathrm{C} / \mathrm{EBP} \alpha, \mathrm{C} / \mathrm{EBP} \beta$, wildtype p53, p21, PTEN, mutated MDM2, caspases, HSP90, COUP-TFI and decorin. In contrast, transfectants expressing ras, src, erbB2, calpastatin, mutated p53 and wild-type MDM2 had low DCI values, indicating increased sensitivity. Thus, it may be possible to predict the sensitivity of cancer cells toward anticancer drugs based on the expression levels of these genes. It should be noted that oncogenes such as ras, $s r c, e r b \mathrm{~B} 2$ and MDM2 increased the chemosensitivity against some, if not all, anticancer drugs whereas tumor suppressor genes such

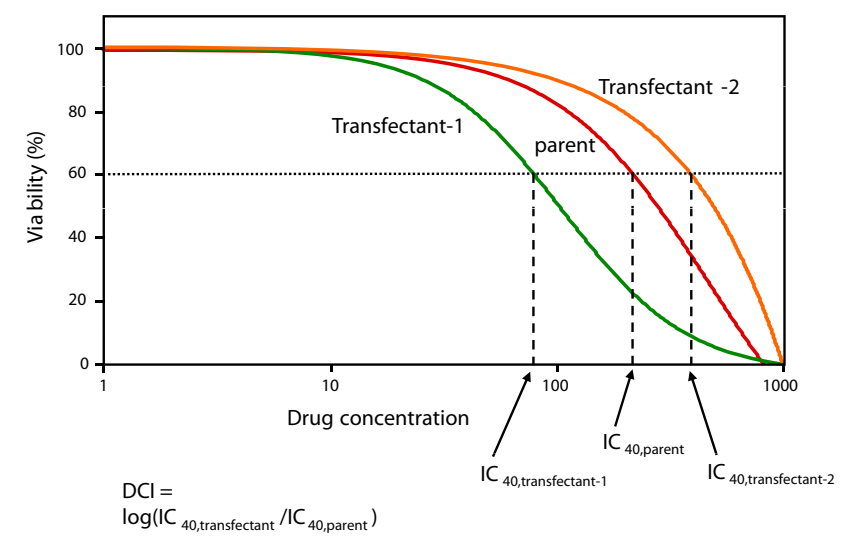

Figure 1: Representative results of the MTT assay. The relative cell viability was measured using the MTT assay. The concentration of drug is shown on the abcissa and the absorbance of the formazan, which represents the relative cell viability, is shown on the ordinate. Sensitivity curves of two transfectants, in addition to the parental ras-NIH3T3 cells, are shown. The positions of drug concentrations giving $40 \%$ inhibition in two transfectants $\left(\mathrm{IC}_{40, \text { transfectant- } 1}\right.$ and $\left.\mathrm{IC}_{40, \text { transfectant- } 2}\right)$ and in the parental cells $\left(\mathrm{IC}_{40, \text { parent }}\right)$ are shown. A dotted line indicates $60 \%(40 \%$ inhibition) of cell viability. Broken lines showed by arrows indicate the concentrations of $\mathrm{IC}_{40, \text { transfectant-1}, ~} \mathrm{IC}_{40 \text {,transfectant-2 }}$ and $\mathrm{IC}_{40 \text {,parent. }} \mathrm{DCl}$ values were calculated and expressed numerically as follows: $\mathrm{DCl}=\log \left(\mathrm{IC}_{40}\right.$ 
Citation: Hiwasa T, Utsumi T, Yasuraoka M, Hanamura N, Shimada H, et al. (2011) Functional Similarity of Anticancer Drugs by MTT Bioassay. J Cancer Sci Ther 3: 250-255. doi:10.4172/1948-5956.1000099

\begin{tabular}{|c|c|c|c|c|c|c|c|}
\hline \multicolumn{2}{|c|}{ CDDP } & \multicolumn{2}{|c|}{ 5-FU } & \multicolumn{2}{|c|}{ MTX } & \multicolumn{2}{|c|}{ СРТ } \\
\hline \multicolumn{2}{|c|}{ Transfected genes } & \multicolumn{2}{|c|}{ Transfected genes } & \multicolumn{2}{|c|}{ Transfected genes } & \multicolumn{2}{|c|}{ Transfected genes } \\
\hline Resistant & Sensitive & Resistant & Sensitive & Resistant & Sensitive & Resistant & Sensitive \\
\hline $\mathrm{C} / \mathrm{EBP} \alpha$ & $\mathrm{N}$-ras & DAN & Ha-ras & $\mathrm{C} / \mathrm{EBP} \alpha$ & v-Src & DAN & Ha-ras \\
\hline $\mathrm{C} / \mathrm{EBP} \beta$ & Ha-ras & $\mathrm{C} / \mathrm{EBP} \alpha$ & TERT-WT & DAN & E2F & HSP90 & N-ras \\
\hline C/EBP $\beta$ & PTEN-A3 & $\mathrm{Bax}^{*}$ & v-Src & Caspase-3 & APP & RhoA-DN & Akt-DN \\
\hline HSP90 & HDAC1 & Hsdj & IкB-TDN & PTEN-G129R & Akt-DN & C/EBP $\beta$ & ErbB2 \\
\hline Hsdj & DJ1-WT & Cystatin $\alpha$ & Axin & p53-WT & Calpain 30K & $\mathrm{C} / \mathrm{EBP} \alpha$ & Calpastatin \\
\hline v-Src & PARK7 & DnaJ & Rac1 & DnaJ & CAMP-PK-CS & Caspase-2 & v-Src \\
\hline COUP & PTEN-G129R & CyclinD1 & PKCg-WT & PKCa-KN & ColXVIII & MKRN1-mut & Ki-ras \\
\hline p21 & Caspase-1 & Caspase-3 & Ki-ras & Ras-N17 & $\mathrm{C} / \mathrm{EBP} \alpha$ & CBP & TERT-WT \\
\hline RhoA-DN & APC & N-ras & STAT5A & P/CAF & WIG1 & PDGF-RD & HDAC1 \\
\hline FANCC & CSK & c-Myc & R-Ras & Decorin & VDAC1 & p16 & FilaminA \\
\hline \multicolumn{2}{|c|}{ VP-16 } & \multicolumn{2}{|c|}{ MIT } & \multicolumn{2}{|c|}{ MMC } & \multicolumn{2}{|c|}{ IFM } \\
\hline \multicolumn{2}{|c|}{ Transfected genes } & \multicolumn{2}{|c|}{ Transfected genes } & \multicolumn{2}{|c|}{ Transfected genes } & \multicolumn{2}{|c|}{ Transfected genes } \\
\hline Resistant & Sensitive & Resistant & Sensitive & Resistant & Sensitive & Resistant & Sensitive \\
\hline DAN & DAP & p53-WT & MDM2-WT & DAN & N-ras & $\mathrm{C} / \mathrm{EBP} \alpha$ & Ras-N17 \\
\hline C/EBP $\beta$ & APC & C/EBP $\beta$ & N-ras & MKRN1-mut & v-Src & TERT-DN & Akt-DN \\
\hline PTEN-WT & PARK7 & CAPN10 & TKT & $\mathrm{C} / \mathrm{EBP} \alpha$ & Ha-ras & Hsp70 & N-ras \\
\hline$P K C \alpha-K N$ & Ha-ras & Bad & PARK7 & C/EBP $\beta$ & ErbB2 & p53-mut & Ki-ras \\
\hline AISEC & HIF1 & PER3 & HDAC1 & C/EBP $\beta$ & Akt-DN & HNF4 & Ha-ras \\
\hline IкB-TDN & STAT4 & c-Myc & Ha-ras & Caspase-2 & p53 & DnaJ & Cystatin E \\
\hline $\mathrm{Bcl}-2$ & STAT6 & TERT-DN & APC & TERT-DN & Ki-ras & p16 & Caspase-1 \\
\hline COUP & OPRT & $\mathrm{Bcl}-2$ & Cyclin D1 & Caspase-3 & TERT-WT & C/EBP $\beta$ & v-Src \\
\hline MDM2-mut & $\mathrm{HO}$ & COUP & MSSP & HSP90 & Calpastatin & MKRN1-mut & WIG1 \\
\hline c-Myc & DJ1-K130R & KRas2-DN & APC & P/CAF & Hsp70 & C/EBP $\beta$ & p53 \\
\hline \multicolumn{2}{|r|}{ PEP } & \multicolumn{2}{|c|}{ ACR } & \multicolumn{2}{|c|}{ VCR } & & axol \\
\hline Trar & ected genes & Tra & ted genes & Tran & cted genes & Tra & cted genes \\
\hline Resistant & Sensitive & Resistant & Sensitive & Resistant & Sensitive & Resistant & Sensitive \\
\hline MKRN1-mut & Ki-ras & DAN & WIG1 & DAN & OPRT & APC & Calpain 30K \\
\hline p53-WT & v-Src & Caspase-2 & PER2 & p53-WT & APC & C/EBP $\beta$ & Axin \\
\hline ARF1 & Cystatin $\alpha$ & p16 & ColXVIII & Decorin & Rap1A & Caspase-2 & TSC1 \\
\hline HSP90 & ErbB2 & Bax & Caspase-1 & DLG & FGFR-KR & Decorin & STAT2 \\
\hline Akt-DN & $\mathrm{N}$-ras & Caspase-3 & Ha-ras & p21 & Rac1 & MDM2-WT & p53-mut \\
\hline PER3 & PARK7 & TERT-DN & TK-1 & C/EBP $\beta$ & APC & DLG & FilaminA \\
\hline DAN & FGFR-WT & Bax & RCC1 & p16 & $\beta$-Catenin & Ki-ras & Akt-DN \\
\hline $\mathrm{BH}$ & HDAC1 & MM1 & Ki-ras & PER3 & CRI1 & Max & STAT3 \\
\hline MDM2-WT & Calpastatin & TS & Cystatin $\alpha$ & PER-1 & RAN & PTEN-WT & HNF4 \\
\hline Caspase-2 & PIGPC1 & Max & ErbB2 & Regucalcin & c-Myc & RhoA-DN & Enigma \\
\hline & MCNU & & -TG & & AraC & & HU \\
\hline Trar & cted genes & Tra & ted genes & Tran & cted genes & Tra & cted genes \\
\hline Resistant & Sensitive & Resistant & Sensitive & Resistant & Sensitive & Resistant & Sensitive \\
\hline C/EBP $\beta$ & Regucalcin & Caspase-3 & APP & C/EBP $\beta$ & AMY1 & DAN & N-ras \\
\hline Rab1A & RAN & $\mathrm{C} / \mathrm{EBP} \alpha$ & PER2 & MKRN1-mut & Gluco-R & $\mathrm{Bcl}-2$ & p21 \\
\hline RhoGDl $\alpha$ & Akt-DN & DAN & ColXVIII & OPRT & Ki-ras & m-Calpain & ErbB2 \\
\hline ARF1 & WIG1 & CaMKIla-CA & CathL-mut & $\mathrm{Bcl}-2$ & Ha-ras & Caspase-3 & HNF4 \\
\hline AISEC & STMN & Cystatina & GUK1 & AISEC & Caspase-3 & TERT-WT & v-Src \\
\hline MDM2-mut & STAT6 & HSP90 & Calpastatin & MDM2-WT & FGFR-KR & TSC1 & Ki-ras \\
\hline $14-3-3 \zeta$ & E2F & C/EBP $\beta$ & RPA2 & Decorin & p53-mut & PTEN-WT & MDM2-WT \\
\hline IKK-DN & Caspase-3 & PDGF-RD & N-ras & Bcl-XL & RAN & Abl & STAT4 \\
\hline$P K C \alpha-K N$ & $\mathrm{C} / \mathrm{EBP} \alpha$ & HSP40 & Ha-ras & PKC $\alpha-K N$ & Bax & HSP90 & PER-1 \\
\hline CAMP-PK-CS & HSP40 & HNF1 & SDC1 & Enigma & HSP90 & R-Ras & CaMKII $\alpha$ \\
\hline
\end{tabular}

Listed are top 10 of genes of which the transfection induced drug resistance or sensitization.

The full version of DCl values are shown in Supplementary Table S1.

Abbreviations: WT, wild-type; mut, mutated; DN, dominant negative; KN, kinase negative; TDN, transdominant negative; CA, constitutively active; CS, catalytic subunit. Table 1: List of anticancer drug-sensitivity-related genes. 
Citation: Hiwasa T, Utsumi T, Yasuraoka M, Hanamura N, Shimada H, et al. (2011) Functional Similarity of Anticancer Drugs by MTT Bioassay. J Cancer Sci Ther 3: 250-255. doi:10.4172/1948-5956.1000099

\begin{tabular}{|c|c|c|c|c|c|c|c|c|c|c|c|c|c|c|c|c|}
\hline & CDDP & 5-FU & MTX & CPT & VP-16 & MIT & MMC & IFM & PEP & ACR & VCR & Taxol & $\mathrm{MCNU}$ & 6-TG & AraC & $\mathrm{HU}$ \\
\hline CDDP & & 0.277 & 0.280 & 0.569 & 0.498 & 0.485 & 0.496 & 0.412 & 0.357 & 0.237 & 0.225 & 0.242 & 0.311 & 0.402 & 0.320 & 0.202 \\
\hline 5-FU & 0.278 & & 0.510 & 0.438 & 0.393 & 0.094 & 0.466 & 0.329 & 0.235 & 0.404 & 0.241 & 0.134 & 0.109 & 0.382 & 0.115 & 0.306 \\
\hline MTX & 0.281 & 0.510 & & 0.484 & 0.426 & 0.275 & 0.515 & 0.355 & 0.407 & 0.350 & 0.358 & 0.180 & 0.173 & 0.523 & 0.229 & 0.356 \\
\hline СРT & 0.568 & 0.438 & 0.484 & & 0.509 & 0.473 & 0.767 & 0.501 & 0.496 & 0.417 & 0.344 & 0.258 & 0.297 & 0.588 & 0.257 & 0.539 \\
\hline VP-16 & 0.498 & 0.393 & 0.426 & 0.509 & & 0.499 & 0.547 & 0.292 & 0.354 & 0.331 & 0.571 & 0.281 & 0.463 & 0.330 & 0.454 & 0.402 \\
\hline MIT & 0.484 & 0.094 & 0.275 & 0.473 & 0.499 & & 0.468 & 0.236 & 0.405 & 0.096 & 0.360 & 0.168 & 0.232 & 0.300 & 0.313 & 0.352 \\
\hline $\mathrm{MMC}$ & 0.496 & 0.466 & 0.515 & 0.767 & 0.547 & 0.468 & & 0.477 & 0.488 & 0.442 & 0.336 & 0.167 & 0.419 & 0.550 & 0.340 & 0.556 \\
\hline IFM & 0.411 & 0.329 & 0.355 & 0.501 & 0.292 & 0.236 & 0.477 & & 0.317 & 0.190 & 0.056 & 0.072 & 0.458 & 0.360 & 0.234 & 0.330 \\
\hline PEP & 0.356 & 0.235 & 0.407 & 0.496 & 0.354 & 0.405 & 0.488 & 0.317 & & 0.346 & 0.208 & 0.152 & 0.280 & 0.342 & 0.368 & 0.332 \\
\hline ACR & 0.232 & 0.404 & 0.350 & 0.417 & 0.331 & 0.096 & 0.442 & 0.190 & 0.346 & & 0.200 & 0.050 & 0.061 & 0.286 & 0.035 & 0.277 \\
\hline VCR & 0.225 & 0.241 & 0.358 & 0.344 & 0.571 & 0.360 & 0.336 & 0.056 & 0.208 & 0.200 & & 0.220 & 0.120 & 0.213 & 0.375 & 0.185 \\
\hline Taxol & 0.242 & 0.134 & 0.180 & 0.258 & 0.281 & 0.168 & 0.167 & 0.072 & 0.152 & 0.050 & 0.220 & & 0.402 & 0.219 & 0.057 & 0.151 \\
\hline MCNU & 0.312 & 0.109 & 0.173 & 0.297 & 0.463 & 0.232 & 0.419 & 0.458 & 0.280 & 0.061 & 0.120 & 0.402 & & 0.135 & 0.425 & 0.234 \\
\hline 6-TG & 0.402 & 0.382 & 0.523 & 0.588 & 0.330 & 0.300 & 0.550 & 0.360 & 0.342 & 0.286 & 0.213 & 0.219 & 0.135 & & 0.168 & 0.394 \\
\hline AraC & 0.320 & 0.115 & 0.229 & 0.257 & 0.454 & 0.313 & 0.340 & 0.234 & 0.368 & 0.035 & 0.375 & 0.057 & 0.425 & 0.168 & & 0.257 \\
\hline $\mathrm{HU}$ & 0.202 & 0.306 & 0.356 & 0.539 & 0.402 & 0.352 & 0.556 & 0.330 & 0.332 & 0.277 & 0.185 & 0.151 & 0.234 & 0.394 & 0.257 & \\
\hline
\end{tabular}

Shown are correlation coefficients between two each of anticancer drugs.

Coefficients higher than 0.5 or lower than 0.2 are marked.

Table 2: Correlation of $\mathrm{DCl}$ values between anticancer drugs.

as p53, p21 and PTEN reduced the sensitivity. This may justify the application of anticancer drugs for cancer therapy.

\section{Regression analysis of DCI values}

Because chemosensitivity was similar but not identical among anticancer drugs, we then performed a regression analysis of the DCI values shown in Table 1 . The correlation coefficients $(r)$ are summarized in Table 2 . The $r$ values were relatively high (significantly correlated) among CDDP, CPT, MMC and VP-16, suggesting that the mechanisms of action of these drugs are similar (Table 2, Figure 2). The $r$ value between MMC and CPT was the highest. The $r$ values of ACR, VCR, taxol and AraC were relatively low (no correlation), suggesting that each of these drugs has a different and unique effect.

Combination chemotherapy is growing more common in cancer chemotherapy. For example, the combination of cyclophosphamide (IFM analogue), VCR and doxorubicin (ACR analogue) is effective for small cell lung cancer [20] and non-Hodgkin lymphoma [21]. The low $r$ value among these drugs means that they works independently. Thus, additive effects can be expected. This was exemplified by the result that the high- $r$-value combination of MIT and PEP caused less cytotoxic effects than the low $r$ value combination of MIT and 5-FU or MTX (Figure 3A)

On the other hand, colon cancer and ovarian clear cell adenocarcinoma are treated with a combination of CPT and MMC [22,23], which showed a high $r$ value (Table 2). Both CPT and MMC are effective toward ras- and erbB2-transfected cells (Table 1). Colon cancers are frequently accompanied by mutations in the Ki-ras gene [24,25]. Overexpression of erbB2 in ovarian carcinoma [26,27] may account for the sensitivity against CPT and MMC. Thus, if the target molecules are restricted, synergistic effects focused on the target can be expected. Furthermore, such high- $r$-value combinations may reduce the side effects caused by a high-dose application of a single drug. Likewise, the high $r$ value combinations of PEP and MTX or VP-16 and MTX showed more suppressive effects than the low $r$ value combinations of PEP and 5-FU or VP-16 and PEP (Figure 3B and C).

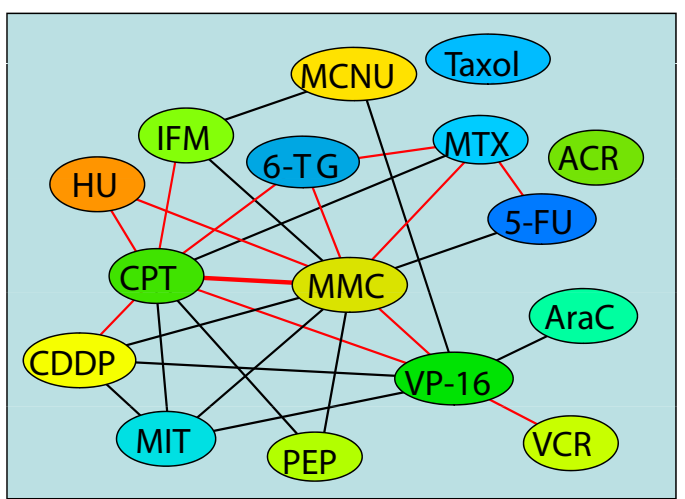

Figure 2: Functional similarity between anticancer drugs. Combinations of two drugs with high $r$ values are shown schematically. High $r$ values suggest similar action mechanisms between drugs. Results in red indicate a closer relationship than results in black. 
Citation: Hiwasa T, Utsumi T, Yasuraoka M, Hanamura N, Shimada H, et al. (2011) Functional Similarity of Anticancer Drugs by MTT Bioassay. J Cancer Sci Ther 3: 250-255. doi:10.4172/1948-5956.1000099

A

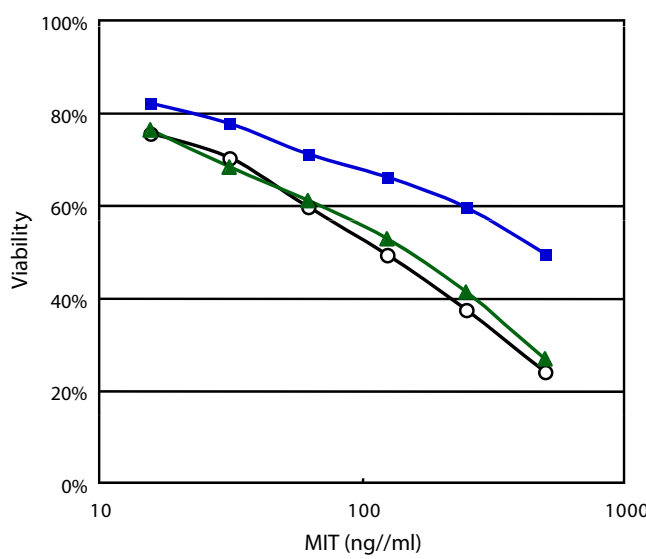

C

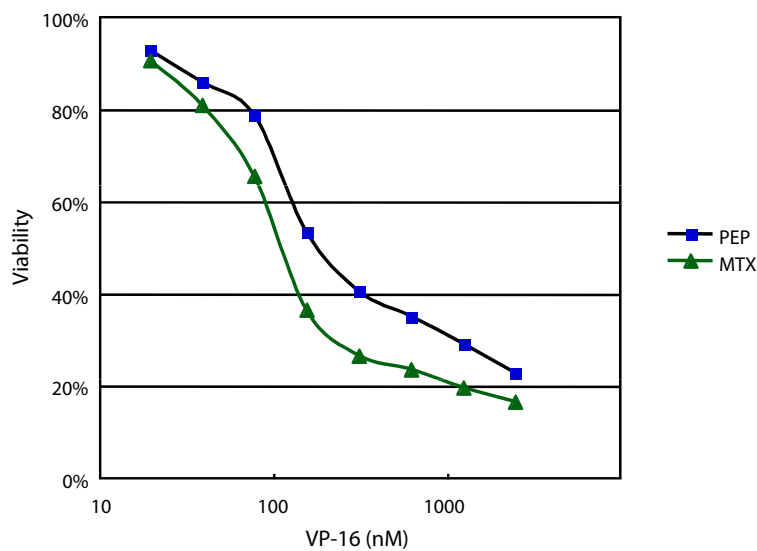

B

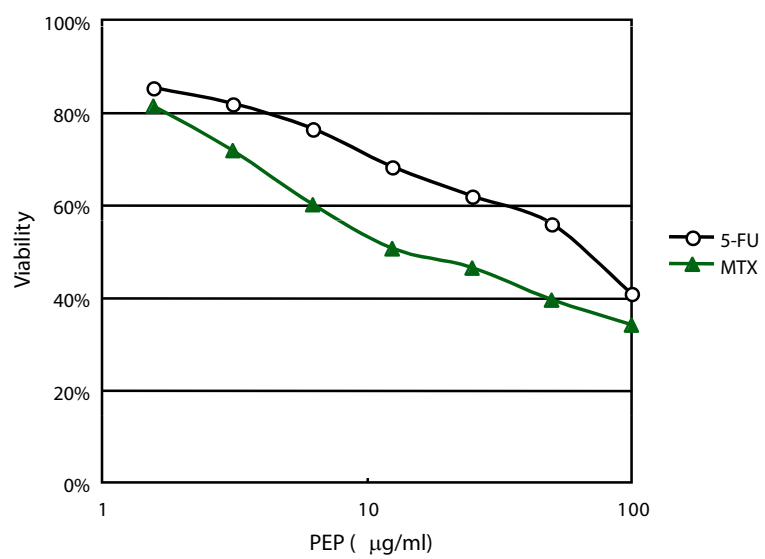

Figure 3: Results of combination treatment. ras-NIH3T3 cells were added with 5-FU (50 ng/ml), PEP (500 ng/ml) or MTX (50 ng/ml). Immediately after the addition, cells were plated in the presence of varying concentrations of MIT (A), PEP (B) and VP-16 (C). After culture for three days, the viabilities were measured by the MTT assay. The abscissa and ordinate represent the concentration of the latter drugs and the relative viability versus that in the absence of the latter drugs, respectively.

Consequently, this approach using regression analysis of DCI values of anticancer drugs may provide a theoretical basis for design of combination chemotherapy regimens.

\section{Acknowledgements}

\section{Grant support}

This work was partly supported by a Grant for 21st Century COE (Center of Excellence) Program and a Grant-in-Aid for Scientific Research from the Ministry of Education, Culture, Sports, Science and Technology of Japan.

We are grateful to Drs. Bert Vogelstein (Howard Hughes Medical Institute), Ygal Haupt (Weizmann Institute of Science), Julian Downward (Imperial Cancer Research Fund), Albert S. Baldwin, Jr. (Lineberger Comprehensive Cancer Center), Lucille A. Lascuola (Dana-Farber Cancer Institute), Daniel A. Bochar (Wistar Institute), Tadashi Akiyama (Waseda University), Tetsu Akiyama (Tokyo University), Sumio Sugano (Tokyo University), Eisuke Nishida (Kyoto University), Shigeo Ohno (Yokohama City University), Toshiharu Suzuki (Hokkaido University), Yu Katayose (Tohoku University), Koichi Suzuki (Toray Industries), Shigeru Sakiyama (Chiba Red Cross Blood Center), Masatoshi Maki (Nagoya University) and Kazumi Ishidoh (Tokushima Bunri University) for providing plasmids. We also thank Ms. Akiko Suganami, Masae Suzuki and Akiko Kimura for their helpful technical assistance.

\section{References}

1. Chen CJ, Chin JE, Ueda K, Clark DP, Pastan I, et al. (1986) Internal duplication and homology with bacterial transport proteins in the mdr1 (P-glycoprotein) gene from multidrug-resistant human cells. Cell 47: 381-389.

2. Kitahara O, Furukawa Y, Tanaka T, Kihara C, Ono K, et al. (2001) Alterations of gene expression during colorectal carcinogenesis revealed by cDNA microarrays after laser-capture microdissection of tumor tissues and normal epithelia. Cancer Res 61: 3544-3549.

3. Luo L, Salunga RC, Guo H, Bittner A, Joy KC, et al. (1999) Gene expression profiles of laser-captured adjacent neuronal subtypes. Nat Med 5:117-122.

4. Ross DT, Scherf U, Eisen MB, Perou CM, Rees C, et al. (2000) Systematic variation in gene expression patterns in human cancer cell lines. Nat Genet 24: 227-235.

5. Scherf U, Ross DT, Waltham M, Smith LH, Lee JK, et al. (2000) A gene expression database for the molecular pharmacology of cancer. Nat Genet 24: 236-244.

6. Dan S, Tsunoda T, Kitahara O, Yanagawa R, Zembutsu H, et al. (2002) An integrated database of chemosensitivity to 55 anticancer drugs and gene expression profiles of 39 human cancer cell lines. Cancer Res 62: 1139-1147.

7. Zembutsu H, Ohnishi Y, Tsunoda T, Furukawa Y, Katagiri T, et al. (2002) Genome-wide cDNA microarray screening to correlate gene expression profiles with sensitivity of 85 human cancer xenografts to anticancer drugs. Cancer Res 62: 518-527.

8. Ooyama A, Takechi T, Toda E, Nagase H, Okayama Y, et al. (2006) Gene 
Citation: Hiwasa T, Utsumi T, Yasuraoka M, Hanamura N, Shimada H, et al. (2011) Functional Similarity of Anticancer Drugs by MTT Bioassay. J Cancer Sci Ther 3: 250-255. doi:10.4172/1948-5956.1000099

expression analysis using human cancer xenografts to identify novel predictive marker genes for the efficacy of 5-fluorouracil-based drugs. Cancer Sci 97 : 510-522.

9. Monks A, Scudiero D, Skehan P, Shoemaker R, Paull K, et al. (1991) Feasibility of a high-flux anticancer drug screen using a diverse panel of cultured human tumor cell lines. J Natl Cancer Inst 83: 757-766.

10. Sekiya T, Fushimi M, Hori H, Hirohashi S, Nishimura S, et al. (1984) Molecular cloning and the total nucleotide sequence of the human c-Ha-ras-1 gene activated in a melanoma from a Japanese patient. Proc Natl Acad Sci U S A 81: 4771-4775.

11. Hiwasa T, Sawada T, Sakiyama S (1996) Synergistic induction of anchorageindependent growth of NIH3T3 mouse fibroblasts by cysteine proteinase inhibitors and a tumor promoter. J Biol Chem 271: 9181-9184.

12. Hiwasa T, Arase Y, Kikuno K, Hasegawa R, Sugaya S, et al. (2000) Increase in ultraviolet sensitivity by overexpression of calpastatin in ultraviolet-resistant UVr-1 cells derived from ultraviolet-sensitive human RSa cells. Cell Death Differ 7: 531-537

13. Liu TL, Shimada H, Ochiai T, Shiratori T, Lin SE, et al. (2006) Enhancement of chemosensitivity toward peplomycin by calpastatin-stabilized NF-kappaB p65 in esophageal carcinoma cells: possible involvement of Fas/Fas-L synergism. Apoptosis11: 1025-1037.

14. Kagaya A, Shimada H, Shiratori T, Kuboshima M, Nakashima-Fujita K, et al (2011) Identification of a novel SEREX antigen family, ECSA, in esophageal squamous cell carcinoma. Proteome Sci 9: 31.

15. Mosmann T (1983) Rapid colorimetric assay for cellular growth and survival: application to proliferation and cytotoxicity assays. J Immunol Methods 65: 5563.

16. Shimada H, Liu TL, Ochiai T, Shimizu T, Haupt $Y$, et al. (2002) Facilitation of adenoviral wild-type p53-induced apoptotic cell death by overexpression of p33(ING1) in T.Tn human esophageal carcinoma cells. Oncogene 21: 12081216.

17. Hiwasa T, Shimada H, Sakaida T, Kitagawa M, Kuroiwa N, et al. (2003) Drugsensitivity pattern analysis for study of functional relationship between gene products. FEBS Lett 552: 177-183.
18. Shiratori T, Shimada H, Kagaya A, Kuboshima M, Nabeya Y, et al. (2007) Sensitization against anticancer drugs by transfection with UBE2I variant gene into ras-NIH3H3 mouse fibroblasts. Anticancer Res 27: 3227-3233.

19. Hiwasa, T. (2006) DSPA, a new method for comprehensive analysis of gene function. Research Signpost Kerala, India.

20. Greco FA, Richardson RL, Snell JD, Stroup SL, Oldham RK (1979) Small cell lung cancer. Complete remission and improved survival. Am J Med 66: 625630

21. Durand M, Chauvergne J, Hoerni-Simon G, Meugé C, De Mascarel A, et al. (1978) [Induction chemotherapy of non-Hodgkin malignant lymphomas. Results of a controlled trial comparing two quadruple associations (author's transl)]. Acta Haematol 59: 80-87

22. Le Page S, Kwiatkowski F, Paulin C, Mohamed F, Pezet D, et al. (2008) In vitro thermochemotherapy of colon cancer cell lines with irinotecan alone and combined with mitomycin C. Hepatogastroenterology 53: 693-697.

23. Nishino K, Aoki Y, Amikura T, Obata H, Sekine M, et al. (2005) Irinotecan hydrochloride (CPT-11) and mitomycin $C$ as the first line chemotherapy for ovarian clear cell adenocarcinoma. Gynecol Oncol 97: 893-897.

24. Bos JL, Fearon ER, Hamilton SR, Verlaan-de Vries M, van Boom JH, et al. (1987) Prevalence of ras gene mutations in human colorectal cancers. Nature 327: 293-297.

25. Forrester K, Almoguera C, Han K, Grizzle WE, Perucho M, et al. (1987) Detection of high incidence of K-ras oncogenes during human colon tumorigenesis. Nature 327: 298-303.

26. Slamon DJ, Godolphin W, Jones LA, Holt JA, Wong SG, et al. (1989) Studies of the HER-2/neu proto-oncogene in human breast and ovarian cancer. Science 244: 707-712.

27. Schwartz DR, Kardia SL, Shedden KA, Kuick R, Michailidis G, et al. (2002) Gene expression in ovarian cancer reflects both morphology and biological behavior distinguishing clear cell from other poor-prognosis ovarian carcinomas. Cancer Res 62: 4722-4729. 